\title{
Applicability of an Analytical Shock/Expansion Solution to the Elevon Control Effectiveness for a 2-D Hypersonic Vehicle Configuration
}

\author{
Torstens Skujins * \\ Carlos E. S. Cesnik ${ }^{\dagger}$ \\ Michael W. Oppenheimer $\ddagger$ \\ David B. Doman $\S$
}

\section{Abstract}

Canard control surfaces placed on the forebody of a hypersonic vehicle provide advantageous characteristics for the vehicle's controllability. This study looked at how these canards affect the flow seen by the elevon control surfaces on the aftbody of the vehicle, and, in turn the controllability of the vehicle in general. A 2-D analytical formulation was compared with CFD Euler solutions. For this analytical formulation, it was found that adding a thickness correction, as opposed to assuming that the airfoils were flat plates, actually decreased on average the accuracy of the model when compared with the computational data. The effect of the canard on the elevon, measured using the elevon effectiveness ratio, decreased as the distance between the control surfaces increased. Higher Mach numbers combined with higher canard deflection angles in general resulted in a greater effect on the elevon.

\section{Introduction}

Among the major issues facing the development of hypersonic vehicles is that of maintaining controllability of the vehicle during the different phases of the flight. Controller development for hypersonic vehicles is very challenging due to the coupling of various parameters affecting vehicle dynamics. The aerodynamics of the vehicle, airframe, propulsion system, and many other aspects all interact with each other and cannot be treated as separate issues. Because of these complicated interactions, computational hypersonic vehicle simulations are a vital tool used in vehicle research and development.

A specific area of importance with regard to vehicle dynamics is the air flow over the various control surfaces on the vehicle. Among different vehicle configurations, a tail-controlled vehicle augmented with a canard in the forebody has gained significant interest recently (e.g., Figure 1). The canards serve two purposes. ${ }^{1}$ First, they give the vehicle the capability to increase pitching moment without changing the overall lift of the vehicle. Second, they assist in low-speed handling. Hypersonic flow around these canards will result in changes in the flow propagating downstream, including shock waves, expansion fans, and a localized change in the freestream flow direction. It is vital to know how these phenomena will interact with the elevon control surfaces in the aftbody and impact their effectiveness. Not taking these effects into consideration can cause misprediction of forces on the elevon that in turn results in potential lack of controllability of the vehicle.

Few publications in open literature exist pertaining to the change in localized flow direction behind a hypersonic airfoil. Airflow turns through two angles (at the front and the rear) while flowing around an

\footnotetext{
*Graduate Research Assistant, University of Michigan, Email: tskujins@umich.edu, Member AIAA.

$\dagger$ Associate Professor, Department of Aerospace Engineering, University of Michigan, Email: cesnik@umich.edu, 1320 Beal Avenue, 3024 FXB, Ann Arbor, MI 48109-2140, Ph. (734) 764-3397, Fax: (734) 764-0578, AIAA Associate Fellow.

${ }_{\ddagger}$ Electronics Engineer, Control Analysis and Design Branch, Air Force Research Laboratory, Email: Michael.Oppenheimer@wpafb.af.mil, Member AIAA.

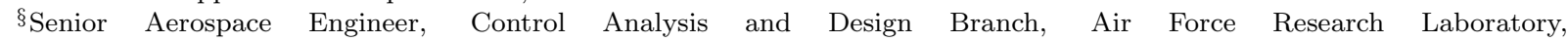
Email: David.Doman@wpafb.af.mil, Senior Member AIAA.
} 


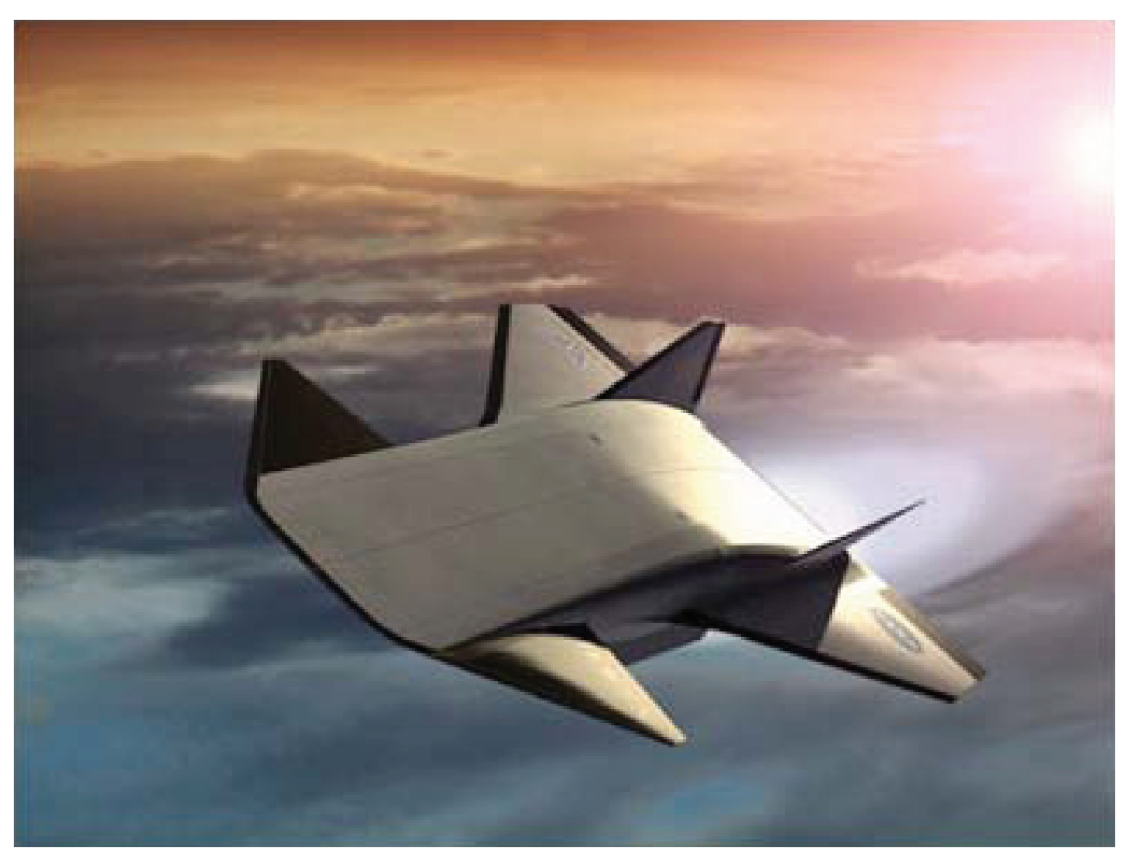

Figure 1. NASA X-43B showing canard and elevon control surfaces

aerodynamic profile at a certain angle of attack. Behind the trailing edge, the pressures of the flow from the top and bottom of the airfoil must be equal, a phenomenon which will be discussed in detail in a subsequent section. Lighthill ${ }^{2}$ originally developed a quantification of a new freestream angle, referred to in this paper as $\alpha^{\prime}$, that is different than the original angle of attack. Oppenheimer et al. ${ }^{1}$ proposed a method based on the numerical solution of the oblique shock and expansion fan equations around a flat plate that compared well with Lighthill's results over a certain range of wedge angles. The authors have shown that the resulting change in localized flow direction at the trailing edge of the canard alone may significantly alter the pressures seen by the elevon in certain flight conditions. In their work, each of the control surfaces was idealized as a flat plate airfoil. A numerical method of calculating the new angle of attack $\alpha^{\prime}$ behind the canard was developed, and the pressures felt by the elevon both considering and not considering the canard were compared. For some flight conditions, especially at higher canard wedge angles, the differences were significant. It was assumed that the flow behind the canard continued at the new value of $\alpha^{\prime}$ all the way back to the elevon without any effect from the freestream flow. Just how far back the new localized flow direction will continue without mixing with the freestream and returning to the pre-canard angle of attack has not been addressed.

The purpose of this paper is to characterize the range of validity of an analytical solution of the oblique shock/expansion equations to obtain the elevon control effectiveness for a two-dimensional (2-D) canard/elevon hypersonic vehicle configuration. The simplified solution will be compared against computational fluid dynamics (CFD) solutions. Oppenheimer and Doman's theoretical 2-D model ${ }^{3}$ will be used as the reference platform. Parametric studies will be carried out by varying flight conditions, control surface angles, and several relative dimensions of the vehicle. This analysis will demonstrate several important factors. First, the range of validity of the analytical shock and expansion fan formulation will be determined. This will be accomplished by comparing the model to CFD results. Second, the CFD analysis will show whether or not the effects of $\alpha^{\prime}$ will still be significant at the location of the elevon or if the flow has returned to its original angle. Third, the CFD analysis will also show if other interaction effects, such as shock and expansion fans from the canard, will play a larger role in affecting the elevon than $\alpha^{\prime}$. These other effects are certainly a significant part of the overall problem, but the scope of this research is limited to looking at the change in localized flow angle. Finally, in the CFD trials, the airfoils are modelled as thin diamond shapes, not flat plates. It will be seen how accurate of an estimate it is for the numerical studies to consider the airfoils as flat plates. For all of these studies, the metric used to measure the effectiveness of the model 
is the elevon effectiveness (i.e., measure of the change in the moment on the elevon per degree of change in elevon deflection). For the CFD trials, the flow will be modelled as inviscid and the air as a perfect gas.

\section{Analytical Oblique Shock and Expansion Fan Formulation}

The analytical oblique shock/expansion formulation to be used in determining elevon control effectiveness for 2-D numerical simulation of hypersonic vehicle flight is presented next.

\section{A. Basic 2-D Flow Geometry}

Consider a supersonic flow over a flat plate with angle of attack $\alpha$ with respect to the flow and a canard deflection angle $\delta_{c}$, as shown in Figure 2.

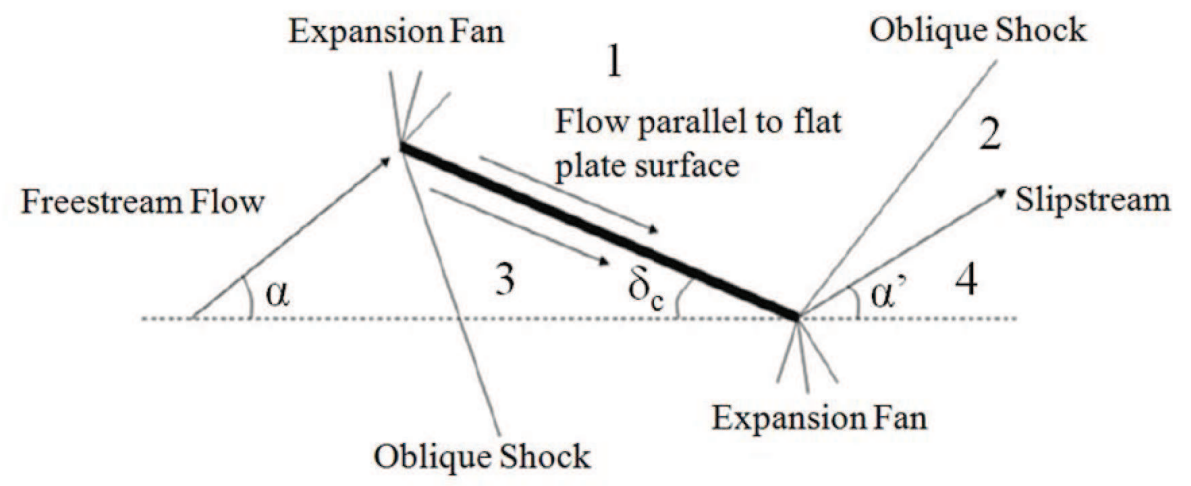

Figure 2. Flow around canard

When the canard effective angle of attack or wedge angle, $\alpha+\delta_{c}$, is positive, flow on the top side of the front of the plate will pass through an expansion fan, which will increase the Mach number while decreasing the pressure. The flow on the bottom will pass through an oblique shock, which decreases the Mach number and increases the pressure. At this point, the flow on both sides of the flat plate is parallel to the surface (canard). At the trailing edge, the streams are deflected so that they are again parallel to each other. The flow over the top will pass through an oblique shock while the flow on the bottom will pass through an expansion fan. The critical aspect here is that the flow direction downstream of the trailing edge is no longer parallel to the freestream flow. Instead, the flow turns through an angle which equalizes the pressure in the flows coming from the top and bottom of the canard; the flow is now at an angle $\alpha^{\prime}$ with respect to the horizontal. A slipstream forms between the flow coming from above and below the canard. Though the pressures in the regions above and below the slipstream are identical, the velocity, density, temperature, and entropy differ, as discussed in detail by Oppenheimer et al. ${ }^{1}$

The model considered in this paper has an elevon located downstream of the canard. As discussed in Oppenheimer et al., ${ }^{1}$ for certain values of $\alpha^{\prime}$, the slipstream from the canard will directly interfere with the elevon. Figure 3 shows this interaction, with the maximum and minimum $\alpha^{\prime}$ values for which the slipstream will hit the elevon. It is assumed here that no mixing occurs between the slipstream and freestream flows.

As illustrated in Figure 3, if $\alpha^{\prime}>\alpha_{\max }^{\prime}$, then the flow below the slipstream will be the one seen by the elevon. If $\alpha^{\prime}<\alpha_{\text {min }}^{\prime}$, then the flow above the slipstream will be seen by the elevon. For cases where the slipstream impacts the elevon, the flow felt by the leading edge of the elevon is used as the incident flow over the entire length of the elevon. The justification for this assumption is that, as the flow hits the tip of the airfoil and passes through an expansion fan and shock, it will turn parallel to the airfoil surface and follow it down its length. As shown on Figure 4, flow on Side A of the slipstream will hit the elevon surface and turn parallel on both sides 1 and 2 of the airfoil. Flow on Side B will turn parallel as well; however, since flow A impacted the tip, it will remain next to the surface for the entire length of the airfoil. Flow B will be 


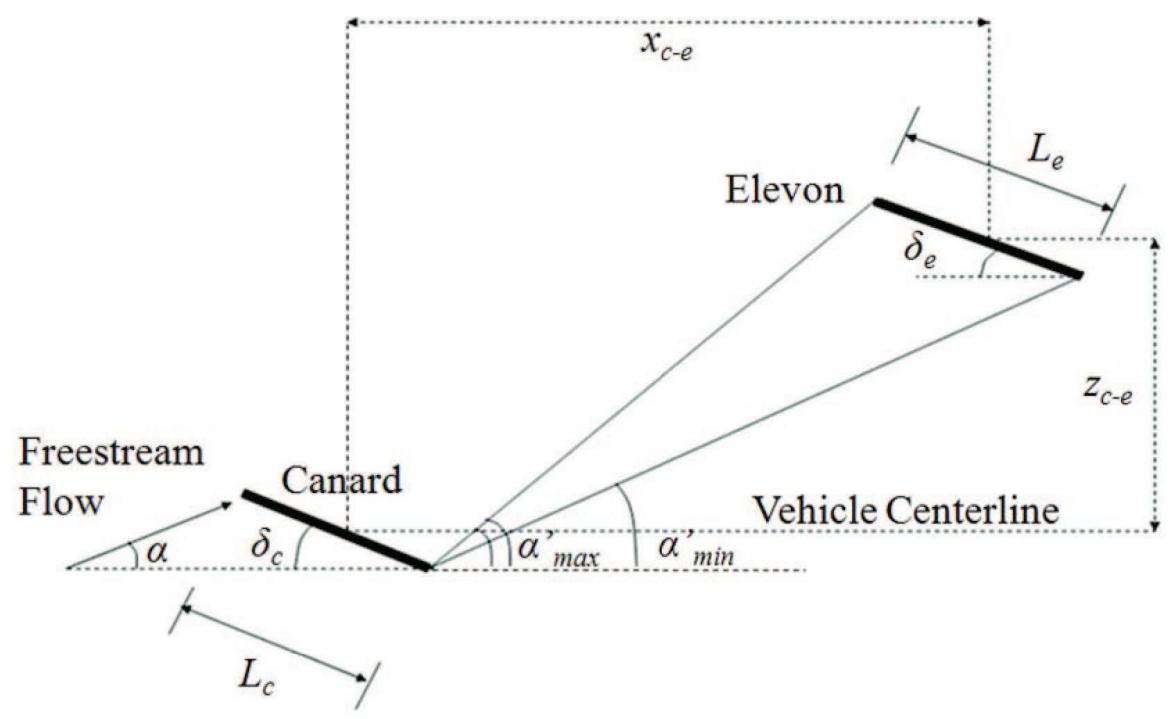

Figure 3. Canard-elevon interactions

remain a distance away from the surface, assuming no mixing effects.

\section{B. Oblique Shock}

All shock wave and expansion fan properties are calculated assuming the airfoil is a flat plate. In the equations that follow, the subscript $L$ refers to quantities before (to the left of) the shock or expansion, and the subscript $R$ refers to the quantities after or to the right of the shock or expansion. At the front of the canard, $M_{L}$ will be freestream flow, $M_{\infty}$. For the trailing edge shock and expansion, $M_{L}$ will be the flow on top or bottom of the airfoil.

For an oblique shock, the shock angle with respect to the freestream is a function of flow turn angle. The shock angle, $\theta_{s}$, can be found by solving the following polynomial for $\sin ^{2} \theta_{s}:{ }^{4}$

$$
\sin ^{6} \theta_{s}+b \sin ^{4} \theta_{s}+c \sin ^{2} \theta_{s}+d=0
$$

where

$$
\begin{gathered}
b=-\frac{M_{L}^{2}+2}{M_{2}^{2}}-\gamma \sin ^{2} \delta \\
c=\frac{2 M_{L}^{2}+1}{M_{L}^{4}}+\left[\frac{(\gamma+1)^{2}}{4}+\frac{\gamma-1}{M_{L}^{2}}\right] \sin ^{2} \delta \\
d=-\frac{\cos ^{2} \delta}{M_{L}^{4}}
\end{gathered}
$$

$\delta$ is the flow turn angle, commonly referred to as the wedge angle, $M_{L}$ is the upstream Mach number, and $\gamma$ $=1.4$ is the ratio of specific heats. The weak shock solution is selected as the answer. Once the shock angle is found, the flow properties can be determined using ${ }^{4}$

$$
\begin{gathered}
\frac{p_{R}}{p_{L}}=\frac{7 M_{L}^{2} \sin ^{2} \theta_{s}-1}{6} \\
\frac{T_{R}}{T_{L}}=\frac{\left(7 M_{L}^{2} \sin ^{2} \theta_{s}-1\right)\left(M_{L}^{2} \sin ^{2} \theta_{s}+5\right)}{36 M_{L}^{2} \sin ^{2} \theta_{s}} \\
M_{R}^{2} \sin ^{2}\left(\theta_{s}-\delta\right)=\frac{M_{L}^{2} \sin ^{2} \theta_{s}+5}{7 M_{L}^{2} \sin ^{2} \theta_{s}-1}
\end{gathered}
$$

where $M_{L}, p_{L}, T_{L}$ are the Mach number, static pressure, and static temperature upstream of the oblique shock and $M_{R}, p_{R}, T_{R}$ are the Mach number, static pressure, and static temperature downstream of the oblique shock. 


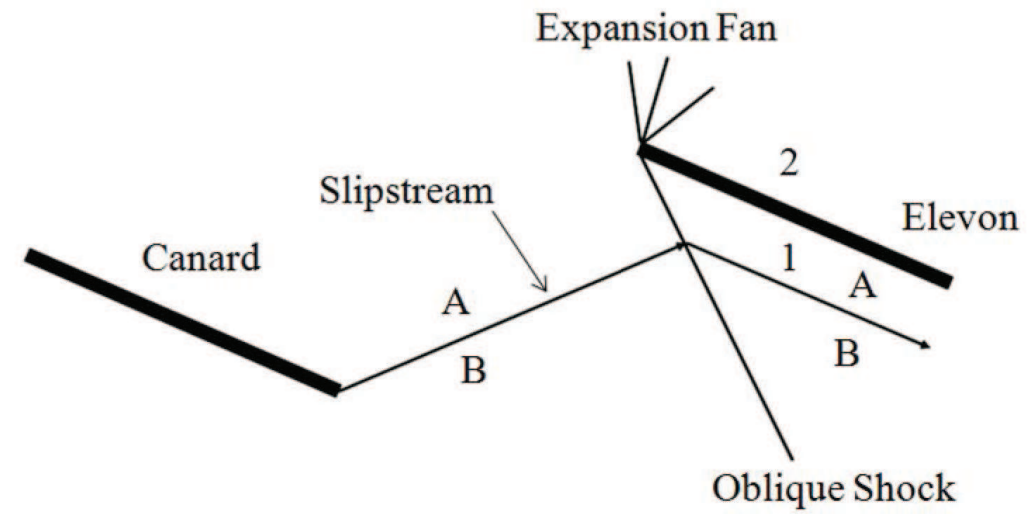

Figure 4. Slipstream incident on elevon

\section{Expansion Fan}

For flow over a convex corner, a Prandtl-Meyer expansion fan occurs. The first step here is to calculate the Prandtl-Meyer function, $\nu_{L}:^{5}$

$$
\nu_{L}=\sqrt{\frac{\gamma+1}{\gamma-1}} \tan ^{-1} \sqrt{\frac{\gamma-1}{\gamma+1}\left(M_{L}^{2}-1\right)}-\tan ^{-1} \sqrt{M_{L}^{2}-1}
$$

The angle, $\nu$, through which the flow is turned is $\nu=\nu_{L}+\delta$ where $\delta$ is the expansion ramp angle. To find the Mach number after the expansion, $M_{R}$, the following equation must be solved numerically

$$
0=\sqrt{\frac{\gamma+1}{\gamma-1}} \tan ^{-1} \sqrt{\frac{\gamma-1}{\gamma+1}\left(M_{R}^{2}-1\right)}-\tan ^{-1} \sqrt{M_{R}^{2}-1}-\nu_{L}
$$

The remaining flow properties are calculated using isentropic flow relations ${ }^{5}$

$$
\begin{gathered}
\frac{p_{R}}{p_{L}}=\left[\frac{1+\frac{\gamma-1}{2} M_{L}^{2}}{1+\frac{\gamma-1}{2} M_{R}^{2}}\right]^{\frac{\gamma}{\gamma-1}} \\
\frac{T_{R}}{T_{L}}=\left[\frac{1+\frac{\gamma-1}{2} M_{L}^{2}}{1+\frac{\gamma-1}{2} M_{R}^{2}}\right]
\end{gathered}
$$

\section{Elevon Effectiveness}

Given the upstream flow properties, $\alpha$, and $\delta_{c}$ as inputs, the properties on the top and bottom of the flat plate are numerically calculated using the analytical oblique shock and Prandtl-Meyer expansion fan equations shown above. These calculations yield the pressures just behind both the shock and expansion fan on the leading edge of the plate along with the other flow properties in regions 1 and 3 of Figure 2. At this point, the flow has been turned parallel to the flat plate. The same oblique shock and expansion fan expressions are then used to determine the properties of the flow at the trailing edge of the canard in regions 2 and 4 of Figure 2. The objective is to find the flow angle, $\alpha^{\prime}$, that yields equivalent upper and lower pressures at the trailing edge of the canard. In other words, referring to Figure 2, find $\alpha^{\prime}$ such that the pressure in region 2 equals the pressure in region 4 . This algorithm then iterates on this angle, such that the difference between the top and bottom pressures behind the canard, equals zero. The starting guess is taken to be the angle $\alpha$. The outputs of the algorithm are the properties of the flow in regions 1, 2, 3, and 4 of Figure 2 along with the angle $\alpha^{\prime}$. 
To find the elevon effectiveness, the static pressure on the top and bottom surfaces of the control surface must first be integrated to determine the aerodynamic forces due to the flow around the elevator under a given angle of attack. Moreover, since the elevator is primarily used for attitude control, the pitching moment due to these forces is calculated. As shown by Oppenheimer et al., ${ }^{1}$ when the effects of the canard are taken into account on the elevon, a significant decrease in moment produced by the elevon can result. These effects are directly seen in terms of elevon effectiveness. In this paper, the elevon effectiveness is computed using a finite difference approach. This result can be normalized by the control effectiveness of the elevon if it were subjected to freestream conditions (and, therefore, independent of the canard deflection):

$$
\text { Elevon Effectiveness Ratio } \equiv \frac{\frac{\partial M_{e}}{\partial \delta_{e}}}{\left.\frac{\partial M_{e}}{\partial \delta_{e}}\right|_{\infty}}
$$

This result will eventually be used as part of a larger simulation code being developed for the longitudinal flight dynamic simulation of hypersonic vehicles. ${ }^{6}$

\section{CFD Analysis}

For this research, the computational fluid dynamics package CFD++ Version 7.1.1, from Metacomp Technologies, was utilized. ${ }^{7}$ The geometries were constructed using the Pointwise, Inc.'s grid generator Gridgen Version 15.11. ${ }^{8}$ Unstructured meshes were created for each trial run and imported into CFD++. Depending on the trial run, between 250 and 300 grid points were placed on each airfoil surface; they were clustered closer together at the ends of the faces to capture the shock and expansion fan effects most accurately. The mesh was also fine in the region between the canard and elevon, as that is the flow region of interest in this study. Figure 5 shows an example mesh with the canard and elevon, while Figure 6 shows a close-up of the elevon.

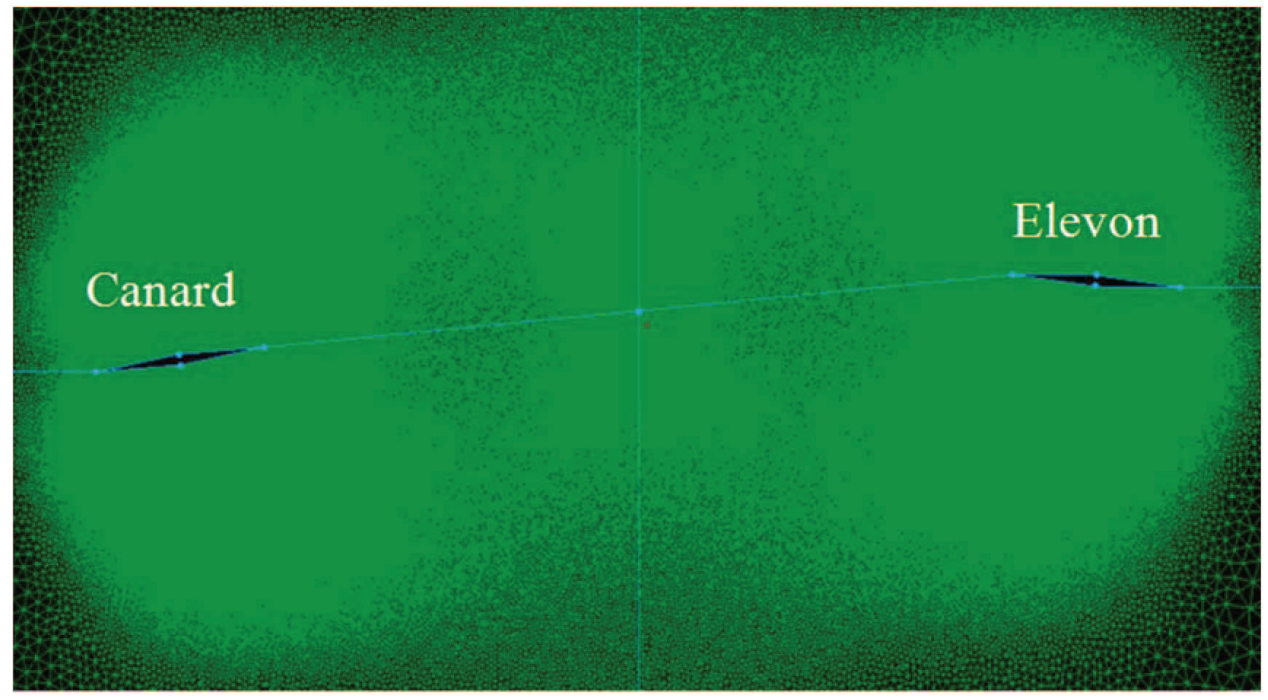

Figure 5. CFD trial run example mesh

In $\mathrm{CFD}++$, Euler solutions were obtained by first starting the runs out with a first-order solver. Then, the solver gradually switched to second-order for the remainder of the run, as recommended in the CFD ++ documentation. ${ }^{7}$ Anywhere from 750 to 1,200 iterations were completed for the trials, which were stopped when the residuals reached a constant value. The air was modelled as a perfect gas.

Before beginning with the actual trial runs, validation cases were conducted. As an example, Figure 7 shows the pressures on each face of a diamond airfoil obtained from the analytical shock/expansion formulation and $\mathrm{CFD}++$. Note that this is a single airfoil without any interference in front of it. Table 1 summarizes the various parameters for this run. As it can be seen, the pressures obtained by using CFD ++ match well with the pressures predicted using the analytical shock/expansion fan formulation, with the two 
Figure 6. Mesh around elevon

Table 1. Validation case parameters

\begin{tabular}{|c|c|c|c|}
\hline $\boldsymbol{M}$ & $\alpha$ & Airfoil Deflection & Mid-Chord Thickness \\
\hline 6.50 & $2.00^{\circ}$ & $0.00^{\circ}$ & $0.040 c$ \\
\hline
\end{tabular}

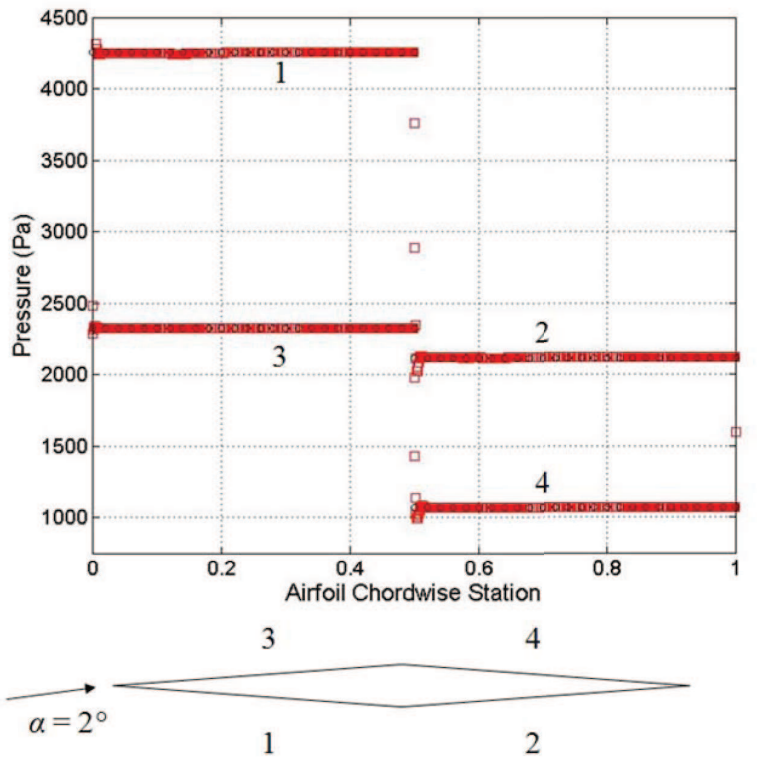

Figure 7. Face pressures for an isolated diamond-shaped airfoil (red-CFD results, black-analytical formulation) 
results falling on top of each other. The symbols along the geometric transition points, that is, the leading edge, mid-chord location, and trailing edge, represent the finite pressure transitions that exist in these regions. Note that, due to the high number of grid points on each airfoil face, the CFD squares are clustered close together and therefore appear to be a solid line.

\section{Parametric Studies}

Parametric studies were conducted in order to evaluate the range of validity of the analytical shock and expansion fan formulation in determining the elevon control effectiveness. Figure 8 shows a parametrization of the 2-D hypersonic model proposed by Oppenheimer et. al. ${ }^{3}$ used for this research. Table 2 summarizes the range of interest for the parameters that will be investigated. There, $M$ is the freestream Mach number, $\alpha$ is the vehicle angle of attack, $\delta_{c}$ is the canard deflection angle, $\delta_{e}$ is the elevon deflection angle, $t$ is the mid-chord airfoil thickness in terms of the canard chord $c, x_{c-e}$ is the horizontal distance from the canard to the elevon, and $z_{c-e}$ is the vertical distance from the canard to the elevon.

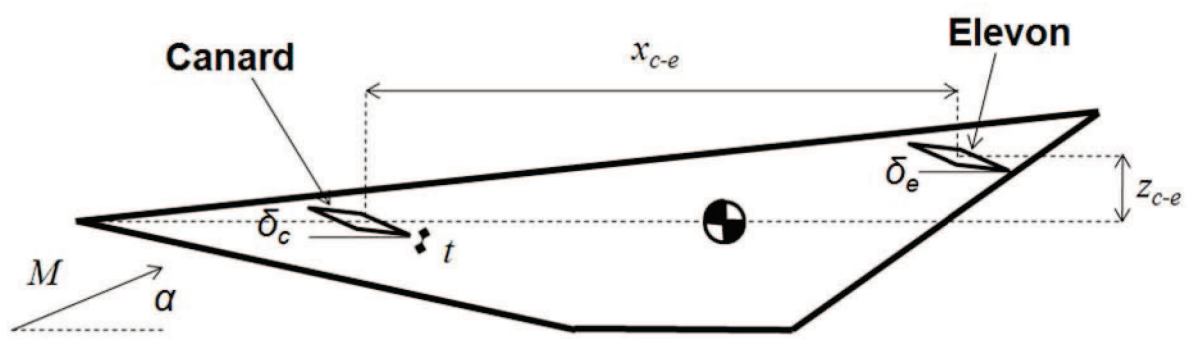

Figure 8. Basic 2D hypersonic vehicle configuration geometry

Table 2. Parametric ranges of interest

\begin{tabular}{|c|c|c|}
\hline Parameter & Minimum & Maximum \\
\hline$M$ & 3.00 & 10.0 \\
\hline$\alpha$ & $-1.00^{\circ}$ & $5.00^{\circ}$ \\
\hline$\delta_{c}$ & $-12.0^{\circ}$ & $12.0^{\circ}$ \\
\hline$\delta_{e}$ & $-15.0^{\circ}$ & $15.0^{\circ}$ \\
\hline$t$ & 0.00 & $0.080 \mathrm{c}$ \\
\hline$x_{c-e}$ & $5.00 \mathrm{c}$ & $12.0 \mathrm{c}$ \\
\hline$z_{c-e}$ & $0.150 \mathrm{c}$ & $0.750 \mathrm{c}$ \\
\hline
\end{tabular}

\section{A. Latin Hypercube Sampling}

In order to most efficiently span the parameter space with the CFD trial runs, nearly-orthogonal Latin hypercube sampling was utilized. For this study, it would have proved to be infeasible to run a trial with each parameter value paired with all the other parameters' values. For example, if only four separate values of each of the seven parameters were considered, the resulting test matrix would have consisted of $4^{7}=16,384$ trial runs. The computational cost of running that many trial runs is prohibitively high.

Nearly orthogonal Latin hypercubes provide a method of spanning the entire parameter space with a relatively small amount of trial runs. ${ }^{9}$ An important characteristic of an orthogonal matrix is that data in none of the columns may have any type of linear relationship with the data in any other column. In creating an orthogonal matrix, each of the parameters are divided into the desired number of values, which are evenly 
spaced throughout the specific parameter's range; the parameter values are then placed in a column. Then, the values of each parameter are paired with the values for the other parameters, taking care not to allow any type of linear relationship between columns. In a nearly orthogonal Latin hypercube matrix, an extremely weak linear relationship between columns is permitted out of necessity. For a parameter space consisting of seven parameters, the ideal number of trials for a nearly orthogonal test matrix is $17 .{ }^{10}$ In order to create the test matrix for this study, the spreadsheet created by Sanchez ${ }^{11}$ was obtained. By inputting the parameters and the ranges of the parameters, the optimal space-filling nearly orthogonal Latin hypercube test matrix was automatically created. This matrix is shown in Table 3.

Table 3. Test matrix

\begin{tabular}{|c|c|c|c|c|c|c|c|}
\hline Trial & $M$ & $\alpha$ & $\delta_{c}$ & $\delta_{e}$ & $t$ & $x_{c-e}$ & $z_{c-e}$ \\
\hline 1 & 5.1875 & 5.000 & 7.5 & -3.750 & $0.020 c$ & $11.5625 c$ & $0.4875 c$ \\
\hline 2 & 3.4375 & 0.500 & 9.0 & 1.875 & $0.000 c$ & $7.1875 c$ & $0.5250 c$ \\
\hline 3 & 3.8750 & 1.625 & -10.5 & -7.500 & $0.050 c$ & $10.6875 c$ & $0.7500 c$ \\
\hline 4 & 4.3125 & 2.750 & -4.5 & 15.000 & $0.045 c$ & $5.8750 c$ & $0.6000 c$ \\
\hline 5 & 8.2500 & 4.625 & -1.5 & -11.250 & $0.025 c$ & $5.0000 c$ & $0.6375 c$ \\
\hline 6 & 10.0000 & 0.875 & -3.0 & 9.375 & $0.005 c$ & $10.2500 c$ & $0.6750 c$ \\
\hline 7 & 7.3750 & 0.125 & 12.0 & -5.625 & $0.070 c$ & $8.0625 c$ & $0.7125 c$ \\
\hline 8 & 6.9375 & 4.250 & 6.0 & 13.125 & $0.065 c$ & $9.3750 c$ & $0.5625 c$ \\
\hline 9 & 6.5000 & 2.000 & 0.0 & 0.000 & $0.040 c$ & $8.5000 c$ & $0.4500 c$ \\
\hline 10 & 7.8125 & -1.000 & -7.5 & 3.750 & $0.060 c$ & $5.4375 c$ & $0.4125 c$ \\
\hline 11 & 9.5625 & 3.500 & -9.0 & -1.875 & $0.080 c$ & $9.8125 c$ & $0.3750 c$ \\
\hline 12 & 9.1250 & 2.375 & 10.5 & 7.50 & $0.030 c$ & $6.3125 c$ & $0.1500 c$ \\
\hline 13 & 8.6875 & 1.250 & 4.5 & -15.000 & $0.035 c$ & $11.1250 c$ & $0.3000 c$ \\
\hline 14 & 4.7500 & -0.625 & 1.5 & 11.250 & $0.055 c$ & $12.0000 c$ & $0.2625 c$ \\
\hline 15 & 3.0000 & 3.125 & 3.0 & -9.375 & $0.075 c$ & $6.7500 c$ & $0.2275 c$ \\
\hline 16 & 5.6250 & 3.875 & -12.0 & 5.625 & $0.010 c$ & $8.9375 c$ & $0.1875 c$ \\
\hline 17 & 6.0625 & -0.250 & -6.0 & -13.125 & $0.015 c$ & $7.6250 c$ & $0.3375 c$ \\
\hline
\end{tabular}

\section{B. Slipstream Tests}

In addition to the Latin hypercube test matrix, a flight condition for which the analytical shock and expansion fan formulation predicted the slipstream to strike the elevon was investigated. The analytical formulation assumes that the slipstream will continue back behind the canard indefinitely. To test how accurate this assertion is, the elevon was moved from a range of three to fifteen chord lengths (horizontally) behind the canard while adjusting the vertical canard-elevon distance such that the slipstream would strike the elevon at a consistent location. Table 4 summarizes the values held constant and used on all of the slipstream tests. Table 5 summarizes the horizontal $\left(x_{c-e}\right)$ and vertical $\left(z_{c-e}\right)$ canard-elevon distances for the trials, which were the only parameters altered on any of the slipstream tests.

\section{Table 4. Slipstream trial run constants}

\begin{tabular}{|c|c|c|c|c|c|c|}
\hline Trial & $M$ & $\alpha$ & $\delta_{c}$ & $\delta_{e}$ & $t$ & Slipstream Impact Location \\
\hline $1 s-6 s$ & 8.00 & $2.50^{\circ}$ & $10.0^{\circ}$ & $5.00^{\circ}$ & 0.00 & $42 \%$ down chord length \\
\hline
\end{tabular}


Table 5. Slipstream trial run variables

\begin{tabular}{|c|c|c|}
\hline Trial & $x_{c-e}$ & $z_{c-e}$ \\
\hline $1 s$ & $3.00 c$ & $0.0750 c$ \\
\hline $2 s$ & $5.00 c$ & $0.213 c$ \\
\hline $3 s$ & $7.00 c$ & $0.350 c$ \\
\hline $4 s$ & $9.00 c$ & $0.488 c$ \\
\hline $5 s$ & $12.0 c$ & $0.695 c$ \\
\hline $6 s$ & $15.0 c$ & $0.902 c$ \\
\hline
\end{tabular}

\section{Analysis Procedure}

For each of the trial runs conducted, the elevon effectiveness ratio was calculated. Because the ratio is found using a finite difference method, as discussed earlier, four separate CFD tests were conducted for each trial run, which are summarized in Table 6.

Table 6. CFD test conditions to evaluate the elevon effectiveness ratio

\begin{tabular}{|c|c|c|}
\hline Test & Canard Present & $\delta_{e}$ \\
\hline 1 & Yes & As specified by test matrix \\
\hline 2 & Yes & $1^{\circ}$ less than specified by test matrix \\
\hline 3 & No & As specified by test matrix \\
\hline 4 & No & $1^{\circ}$ less than specified by test matrix \\
\hline
\end{tabular}

The resultant forces on the elevon in the CFD trials were found by numerically integrating the pressures on the airfoil. In order to eliminate effects due to numerics at the leading and trailing edges of the airfoil faces, the pressures from $10 \%$ to $90 \%$ of the airfoil face length were used. Once the pressures were obtained, the resultant forces on the face were found by using a trapezoidal rule numerical integration scheme, i.e.,

$$
F=\sum \frac{1}{2}[p(x+\Delta x)+p(x)] \Delta x
$$

where $F$ is the resultant force on the airfoil face, $p(x)$ is the pressure at the grid point located at $x$, and $\Delta x$ is the distance between two consecutive grid points. The resultant forces on the airfoil faces were broken down into horizontal and vertical components. Then, the total horizontal and vertical forces on the elevon were found by summing the components of the forces on each face. Next, the moment due to the elevon about the vehicle's center of gravity was calculated, assuming that the center of gravity is located $\frac{4}{7}$ of the way horizontally from the canard to the elevon down the body axis, as shown in Figure 9 and

$$
\frac{x_{\text {canard }}}{x_{\text {canard }}+x_{\text {elevon }}}=\frac{4}{7}
$$

Vertically, the center of gravity is in line with the canard. These dimensions are exactly the same as the ones used by Oppenheimer and $\operatorname{Doman}^{3}$ and serve to standardize the moment calculations by making the ratio of the elevon x-moment arm and $x_{c-e}$ constant. Finally, the finite difference method discussed previously was used to calculate the elevon effectiveness ratio for each trial run.

\section{Results and Discussion}

\section{A. Slipstream Observations}

Before the elevon effectiveness ratio results obtained from the trials, it was necessary to study the existence of the slipstream itself. Figures 10, 11, and 12 show the Mach contours of the trials described in Tables 4 


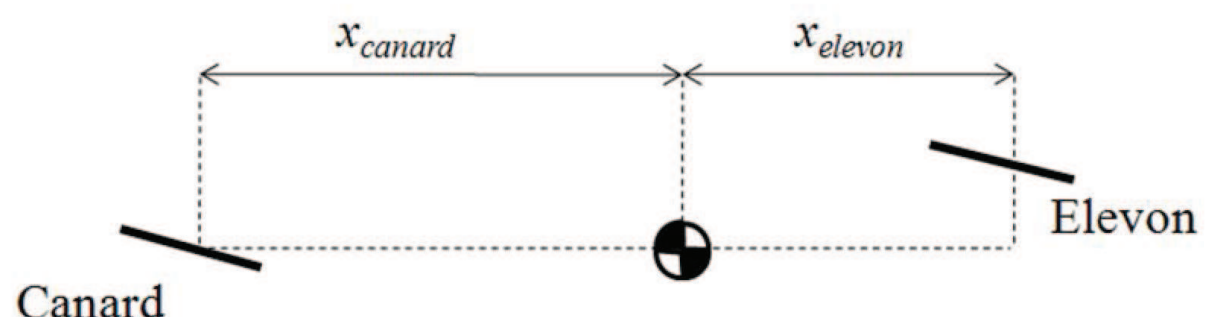

Figure 9. Geometry used for moment calculations

and 5 with canard-elevon separations of 3.00, 7.00, and 12.0 chord lengths, respectively.

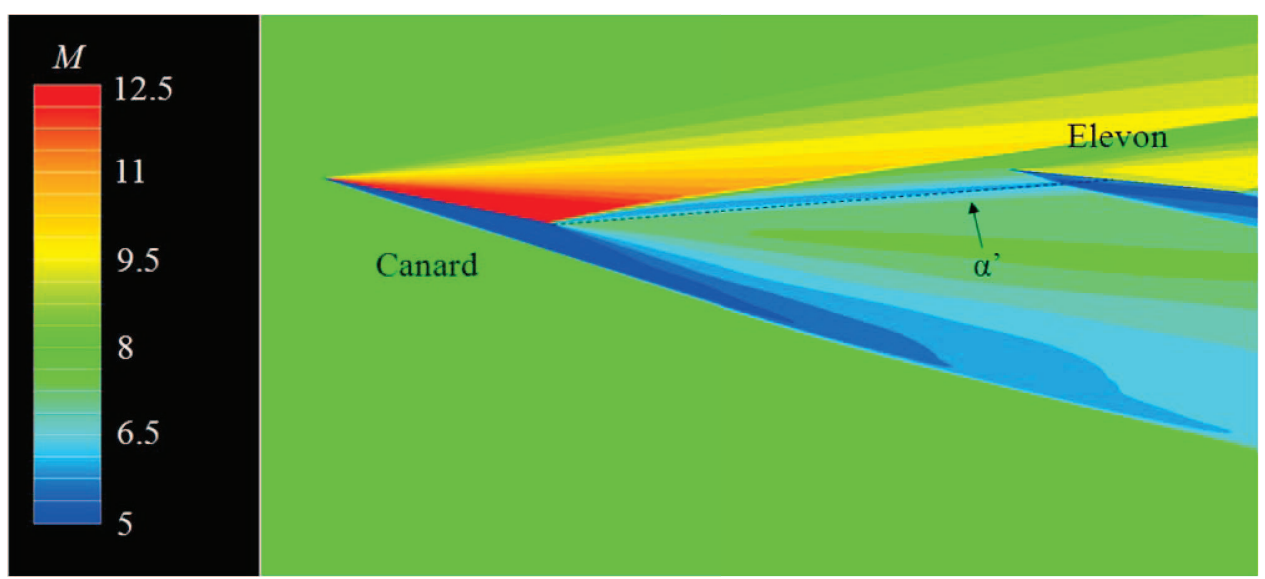

Figure 10. Mach contours for canard-elevon horizontal distance $3 c$

The slipstream can be clearly seen in the figures, as indicated by the transition of the contours from green to blue near the superimposed dashed line, which shows the location of the slipstream as calculated by the analytical formulation. It appears that, as the slipstream travels farther downstream, it is affected by flow with values closer to that of freestream. As it does so, the slipstream appears to gradually change directions and move at an angle closer to the freestream $\alpha$, as shown in Figure 12. Also, as the perpendicular distance away from the slipstream is increased, the flow conditions become closer to the pre-canard freestream values than the values predicted by the analytical formulation for above and below the slipstream.

\section{B. Latin Hypercube Test Matrix}

Table 7 summarizes the elevon effectiveness ratio results calculated for the trials defined by the Latin hypercube test matrix. Note that two separate analytical shock/expansion fan calculations were used. The first, labelled "Analytical, Thick" in the table, included the thickness effects of the diamond airfoil. The second, labelled "Analytical, Flat," assumed that all of the airfoils were flat plates. The percent error columns refer to the differences between the respective analytical formulation and the CFD results. Also, note that the mean percent error and the standard deviation at the bottom of Table 7 are with respect to error values from each column.

The results from Table 7 show that the analytical shock and expansion fan formulation assuming a flat plate agrees more closely in average with the CFD test results than the formulation taking thickness into consideration. There are several cases in which the thickness corrections improve the correlations with CFD. However, in those cases, the error is already small, typically less than $3 \%$. For example, Trial 5 shows 


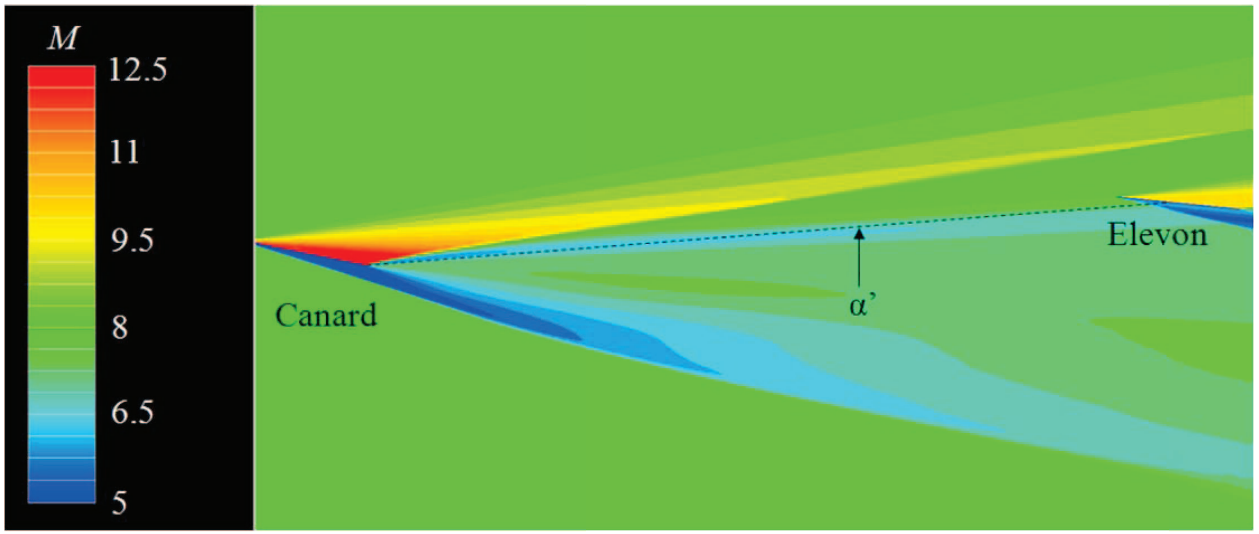

Figure 11. Mach contours for canard-elevon horizontal distance $7 c$

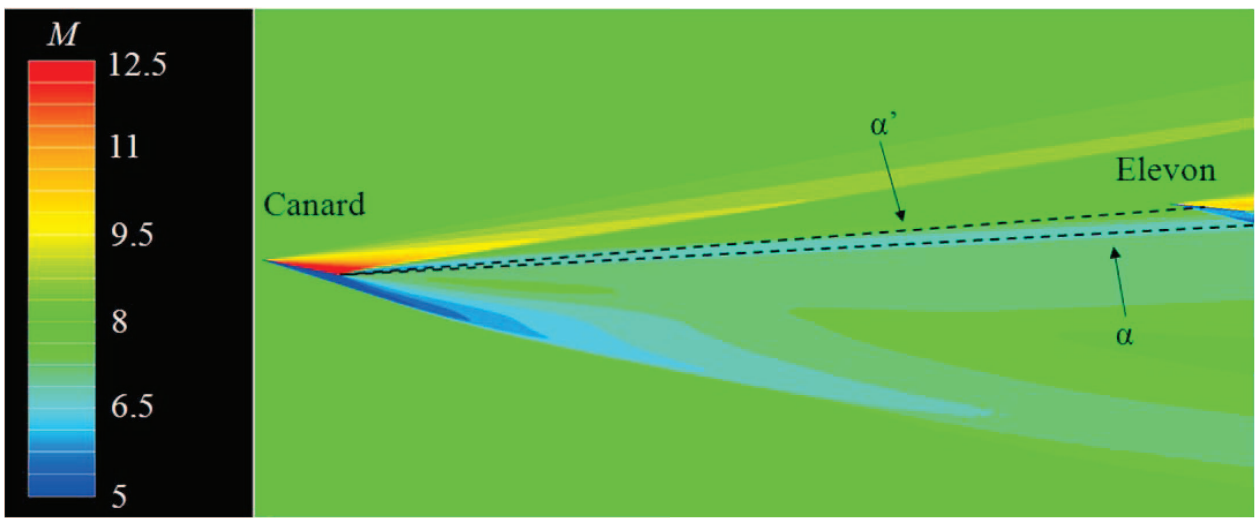

Figure 12. Mach contours for canard-elevon horizontal distance $12 c$ 
Table 7. Elevon effectiveness ratio results

\begin{tabular}{|c|c|c|c|c|c|}
\cline { 2 - 6 } \multicolumn{1}{c|}{} & \multicolumn{3}{c|}{ Elevon Effectiveness Ratio } & \multicolumn{1}{c|}{} \\
\hline Trial & CFD & Analytical, Thick & Analytical, Flat & Percent Error: Thick & Percent Error: Flat \\
\hline 1 & 0.949 & 0.908 & 0.928 & 4.36 & 2.29 \\
\hline 2 & 0.988 & 0.984 & 0.984 & 0.445 & 0.445 \\
\hline 3 & 0.958 & 0.973 & 0.987 & -1.57 & -3.10 \\
\hline 4 & 0.930 & 0.997 & 1.00 & -7.22 & -7.56 \\
\hline 5 & 0.972 & 0.970 & 0.991 & 0.257 & -1.90 \\
\hline 6 & 0.979 & 0.993 & 0.995 & -1.45 & -1.66 \\
\hline 7 & 0.772 & 0.364 & 0.636 & 52.9 & 17.6 \\
\hline 8 & 0.762 & 0.781 & 0.782 & -2.56 & -2.64 \\
\hline 9 & 0.992 & 0.991 & 0.999 & 0.111 & -0.695 \\
\hline 10 & 0.892 & 0.781 & 0.909 & 12.4 & -1.86 \\
\hline 11 & 0.993 & 0.617 & 0.938 & 37.9 & 5.59 \\
\hline 12 & 0.728 & 0.639 & 0.715 & 12.3 & 1.89 \\
\hline 13 & 0.884 & 0.874 & 0.944 & 1.08 & -6.79 \\
\hline 14 & 0.965 & 0.996 & 1.00 & -3.18 & -3.60 \\
\hline 15 & 0.961 & 0.988 & 0.998 & -2.80 & -3.78 \\
\hline 16 & 0.975 & 0.928 & 0.941 & 4.84 & 3.47 \\
\hline 17 & 0.924 & 0.970 & 0.979 & -5.03 & -5.94 \\
\hline & & & $\mathbf{8 . 8 5}$ & $\mathbf{4 . 1 7}$ \\
\cline { 2 - 6 } & Compound Standard Deviation: & $\mathbf{1 4 . 5}$ & $\mathbf{4 . 0 3}$ \\
\hline
\end{tabular}


that including the thickness of the airfoil reduces the error from $-1.90 \%$ to $0.26 \%$. On the other hand, the analytical formulation with thickness for Trial 11, which with a mid-chord thickness of $8.00 \%$ is the thickest one considered, differs from the CFD results by $37.9 \%$, while the flat plate formulation differs by only $5.59 \%$. For this case, the thickness formulation predicts a Mach number of 8.90 above the slipstream and 7.57 below the slipstream, compared with a freestream value of 9.56. Figure 13 shows the Mach number contours of this trial case. Figure 14 shows an expanded view of box A in Figure 13.

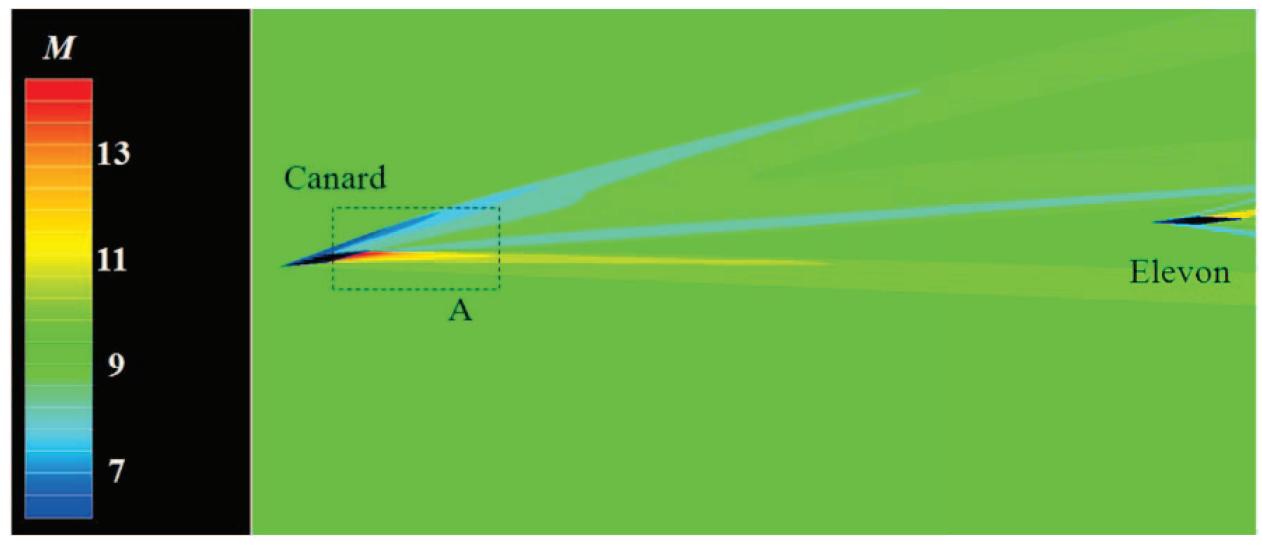

Figure 13. Mach contours of Trial 11

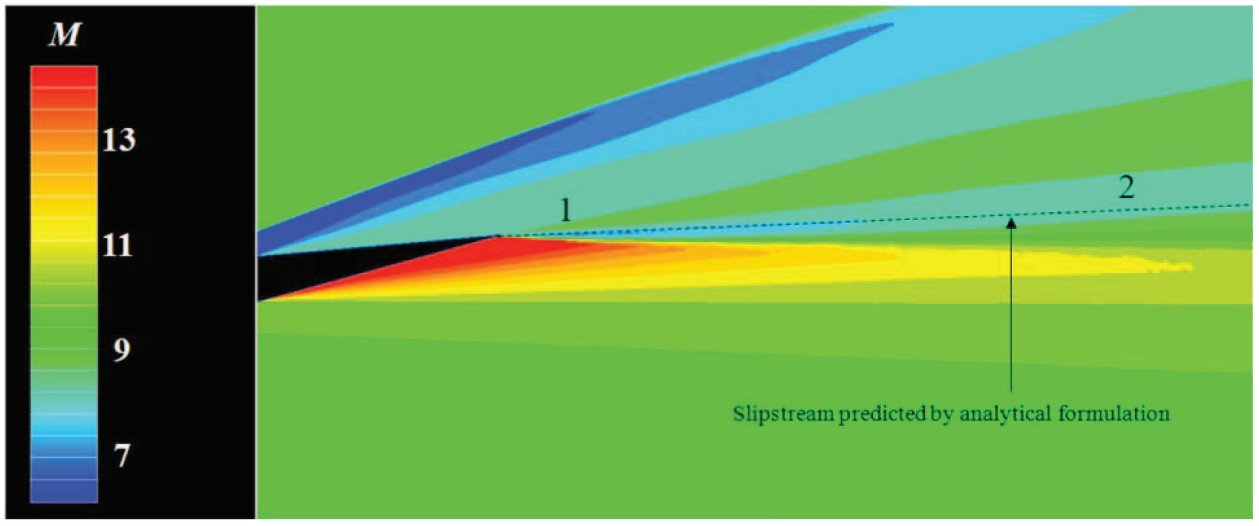

Figure 14. Close-up of Mach contours for Trial 11

Around location 1 in Figure 14 the Mach numbers on each side of the slipstream, marked in the figure, do match fairly well with those predicted by the thickness formulation. However, by the time the flow has reached location 2, the Mach numbers, while not completely back to freestream values, have increased, displayed by the fact that the darker blue colors have gone away. This shows that the lower Mach numbers predicted by the thickness formulation behind the trailing edge of the airfoil are relatively local effects, dissipating with distance. Though the slipstream, and hence the slightly lower Mach numbers, continues back to the area around the elevon, the Mach numbers are higher than predicted by the thickness formulation. Also, away from the slipstream, the Mach numbers increase with distance due to freestream interactions. The analytical formulation assumes that the flow conditions directly above and below the slipstream at the trailing edge continue both backwards and away from the slipstream. As shown in the contour plots, the thickness effects do not extend very far behind the airfoil. The flat plate formulation does not predict as extreme of a Mach number change behind the canard, returning Mach numbers above and below the slipstream of 9.38 and 9.21, respectively, for Trial 11. As such, the flat plate formulation in many cases were proven to be the more accurate model.

Two trial runs (not including Trial 7, which was impacted by the canard's shock/expansion fan system) 
had significantly lower elevon effectiveness ratios: Trial 8 (0.762) and Trial $12(0.728)$; the next lowest was Trial $13(0.874)$. Trials 8 and 12 had relatively large Mach number/canard wedge angle $\left(\alpha+\delta_{c}\right)$ combinations, $6.94 / 10.2^{\circ}$ and $9.12 / 12.9^{\circ}$, respectively. Only Trial $1\left(12.5^{\circ}\right)$ and Trial $7\left(12.1^{\circ}\right)$ had larger canard wedge angles, but Trial 1 had a lesser Mach number. Analytical calculations show that as the Mach number and canard wedge angle increase, the flow behind the canard deviates more from the freestream flow. ${ }^{1}$ These results show that this agreement holds true for a computational Euler solution of the flowfield.

\section{Other Interaction Effects}

Looking at the results in Table 7, Trial 7 has the largest percent error for both the flat plate (17.6\%) and thickness $(52.9 \%)$ formulations. The reason for these large differences becomes apparent when looking at the pressure contours of this trial, as shown in Figure 15.

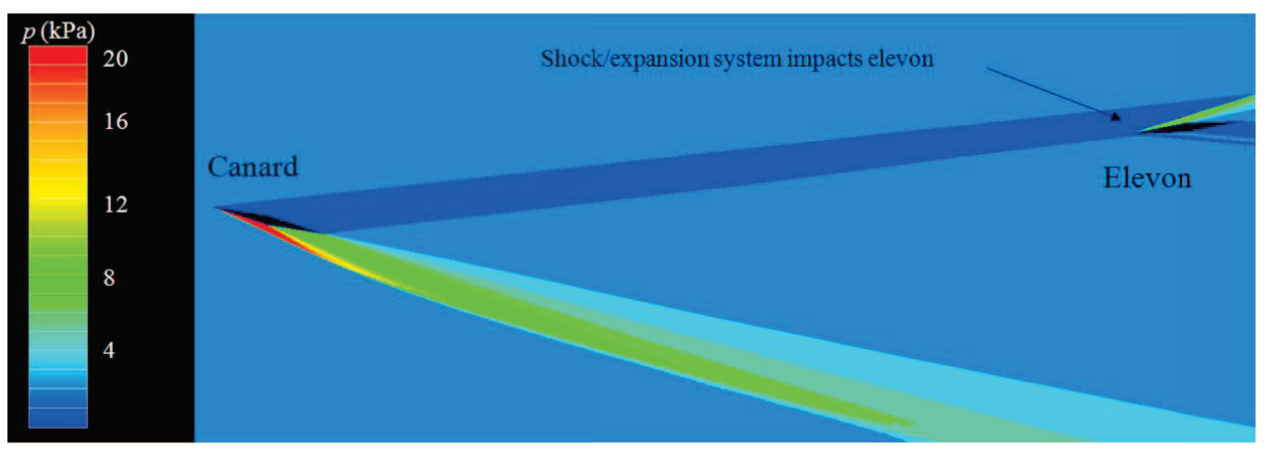

Figure 15. Pressure contours for Trial 7

The shock/expansion fan system from the top of the canard travels downstream and impacts the elevon. The analytical formulation does not take into account the possibility of shocks and expansion fans directly impacting the elevon. As a result, the effectiveness predictions for situations when this occurs will not be as accurate. This was the only test matrix trial where this situation was encountered. Therefore, if this run is not included in the mean and standard deviation calculations, the new values, again in terms of the compound value of the error, are as shown in Table 8. Also, note that the improvement in the table is the absolute amount by which the percent error improved, and "Thickness" and "Flat Plate" refer to the analytical formulations assuming thickness and flat plate, respectively.

Table 8. Compound mean error and standard deviation without considering Trial 7 results

\begin{tabular}{|c|c|c|c|c|}
\cline { 2 - 5 } \multicolumn{1}{c|}{} & Thickness & Flat Plate & Improvement, Thick. & Improvement, Flat. \\
\hline Mean & 6.10 & 3.33 & 2.75 & 0.840 \\
\hline Standard Deviation & 9.30 & 2.13 & 4.89 & 1.90 \\
\hline
\end{tabular}

\section{Slipstream Trial Results}

Figure 16 is a plot of the elevon effectiveness ratio of the trials detailed in Table 5 as a function of the horizontal canard-elevon distance. In this section, Side A refers to the side of the slipstream impacting the front of the elevon (see Figure 4). Prior to this research, the flow conditions on this side were used any time the slipstream impacted the elevon. Side B is the opposite side of the slipstream.

Table 9 shows the percent error between the CFD-calculated elevon effectiveness ratios and those calculated by the analytical formulations considering the two flow conditions: Side A and Side B of the slipstream.

From Figure 16 and Table 9, it is clear that the effect of the slipstream on the elevon diminishes with increasing canard-elevon distance. In fact, by the time the horizontal distance reaches 12 chord lengths, the effectiveness ratio has almost returned to its freestream value of 1 . Also, for each case, Side B proved to be the closer approximation; in fact, at a horizontal distance of 3 chord lengths, the error with respect to the 


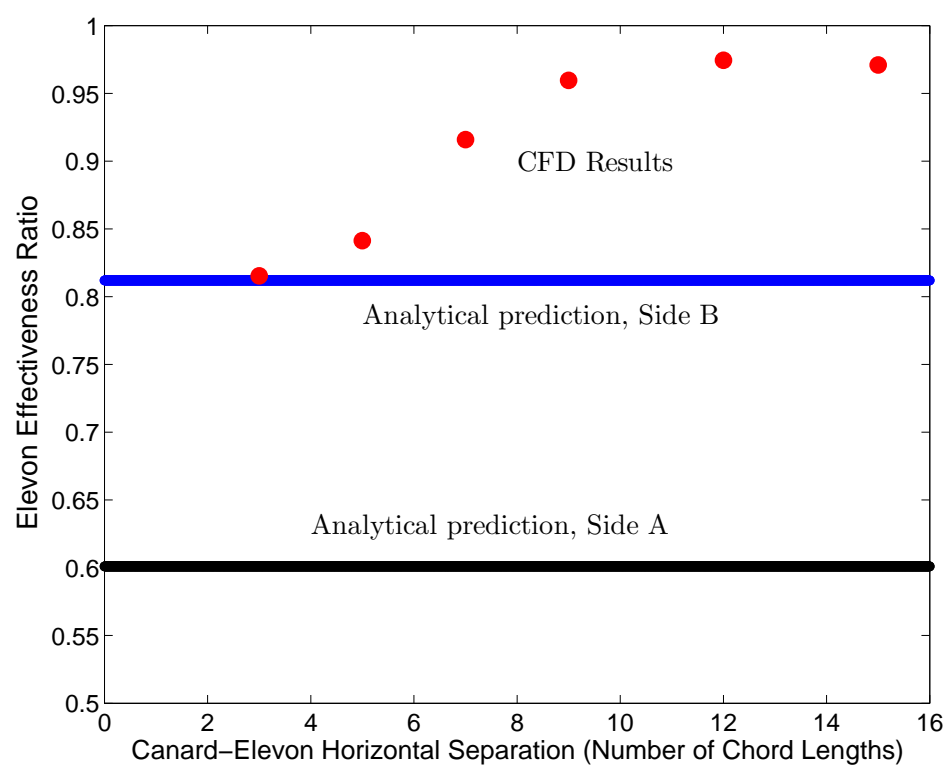

Figure 16. Impact of the distance between canard and elevon on the elevon performance

Table 9. Slipstream trial errors with respect to CFD results

\begin{tabular}{|c|c|c|}
\hline Canard-Elevon Horizontal Distance & Percent Error, Side A & Percent Error, Side B \\
\hline $3.00 c$ & 26.2 & 0.340 \\
\hline $5.00 c$ & 28.5 & 3.49 \\
\hline $7.00 c$ & 34.4 & 11.4 \\
\hline $9.00 c$ & 37.1 & 15.0 \\
\hline $12.0 c$ & 38.4 & 16.7 \\
\hline $15.0 c$ & 38.1 & 16.4 \\
\hline
\end{tabular}


CFD trial was less than $1 \%$. For these trials, the slipstream struck the elevon about $42 \%$ of the way down its chord length, meaning that, if the slipstream were to continue all the way to the airfoil surface, more of the surface would see flow from Side B (beneath the slipstream) than Side A (above the slipstream).

In order to see how the effectiveness ratio changes depending on where the slipstream strikes the surface, three additional trials were run; they are summarized in Table 10. Note that for the slipstream-elevon intersection point, $100 \%$ would refer to the slipstream striking the trailing edge of the elevon. Table 11 summarizes the results in terms of the errors encountered by the analytical formulation.

Table 10. Additional slipstream trial parameters

\begin{tabular}{|c|c|c|c|}
\hline Trial & Horizontal Distance & Vertical Distance & Slipstream-Elevon Intersection Point \\
\hline$A 1$ & $3.00 c$ & $0.110 c$ & $66 \%$ \\
\hline$A 2$ & $3.00 c$ & $0.150 c$ & $91 \%$ \\
\hline$A 3$ & $5.00 c$ & $0.280 c$ & $86 \%$ \\
\hline
\end{tabular}

Table 11. Additional slipstream trial results

\begin{tabular}{|c|c|c|c|}
\hline Trial & CFD Elevon Effectiveness Ratio & Percent Error, Side A & Percent Error, Side B \\
\hline$A 1$ & 0.829 & 27.4 & 1.99 \\
\hline$A 2$ & 0.609 & 1.35 & -33.2 \\
\hline$A 3$ & 0.917 & 34.5 & 11.5 \\
\hline
\end{tabular}

From Table 11, Side B agrees with the CFD results much more closely than Side A for trial $A 1$, which is consistent with the prior observation. For Trial $A 2$, Side A agrees much more closely. However, for this trial, the shock/expansion fan system from the canard directly interferes with the elevon. Figure 17 displays the Mach contours for this situation.

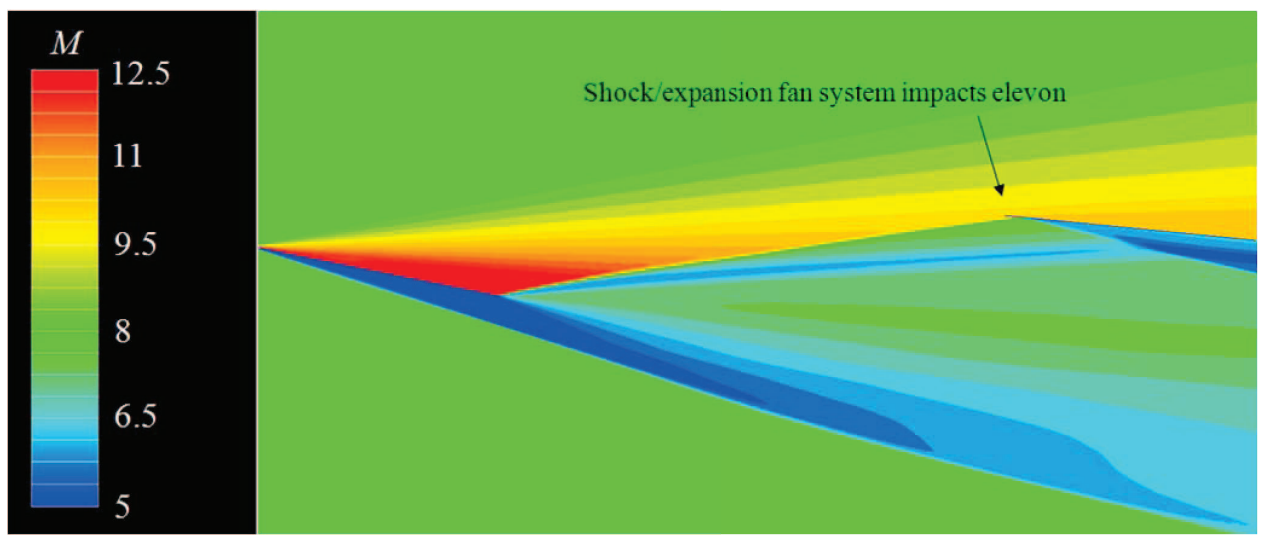

Figure 17. Expansion fan-elevon interactions, Trial $A 2$

Trial $A 3$ was conducted in order to help determine the impact of the shock/expansion fan system on the elevon effectiveness ratio. By moving slightly further downstream, the elevon was able to be positioned at a location such that the slipstream would still strike very close to the back, thereby theoretically allowing flow on Side A to impact much of the elevon while still keeping the elevon out of the canard's shock/expansion fan system, as shown in Figure 18.

Neither one of the analytical formulation predictions came within $10 \%$ of the CFD value. This is possibly due to two factors. The first, as mention previously, is that the flow properties move closer to freestream property values as the perpendicular distance away from the freestream increases. Since the slipstream is 


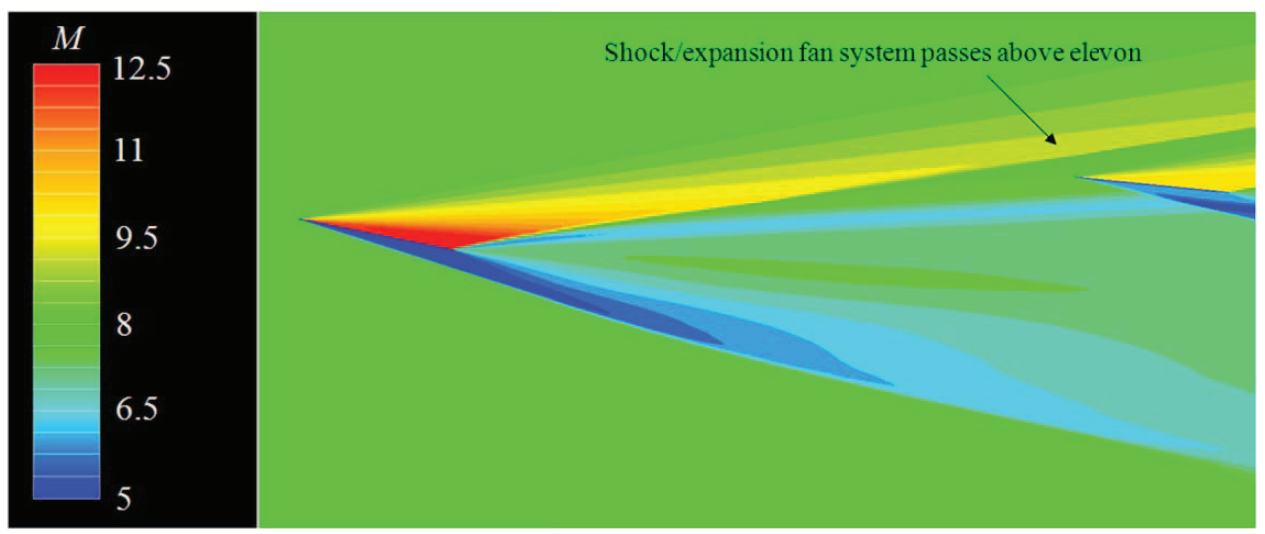

Figure 18. Expansion fan-elevon interactions, Trial $A 3$

striking the very back of the elevon, it is possible that the front and middle are experiencing flow that has much different properties. The second factor is that, though the shock/expansion fan system does not directly strike the elevon, its close proximity could have some effect on how far the slipstream effects propagate into the flow field.

\section{Conclusions}

The CFD results have shown that for an Euler solution, the slipstream behind the trailing edge of an airfoil does in fact impact the control effectiveness of the elevon. Trial runs showed that the slipstream's effect on the elevon diminishes with increased distance away from the airfoil, suggesting that interactions with near-freestream flow conditions serve to weaken it. By a canard-elevon separation of twelve chord lengths, the flow impacting the elevon, as measured by the elevon effectiveness ratio, had very nearly returned to freestream. This assertion is also supported by the fact that the slipstream begins to curve as it moves downstream to an angle closer to $\alpha$ than $\alpha^{\prime}$. However, its initial angle is closer to the predicted $\alpha^{\prime}$.

Overall, the elevon effectiveness ratios predicted by the analytical formulation assuming flat plate airfoils were closer to the CFD results than the formulation with thickness effects included. Though for a few cases the thickness corrections provided results that more closely matched the CFD data, the overall error for both the flat plate and thickness calculations for these cases was relatively small, as detailed in Section VII, Part A. The Mach numbers directly above and below the slipstream predicted by the analytical formulation with thickness corrections are less than those predicted with the flat plate assumption and decrease as thickness increases. However, the CFD results showed that these relatively low Mach numbers were very localized effects just behind the trailing edge which dissipated quickly. Therefore, using the flow properties obtained through the thickness correction does not improve the predictive accuracy of the analytical formulation, and the simple flat plate representation of the airfoil may be used.

When the slipstream impacted the airfoil, the elevon effectiveness ratios predicted by using the conditions on Side B (the flow not hitting the tip of the elevon) were generally closer than those predicted by using the conditions on Side A. The only case in which the prediction using Side A was closer was trial $A 2$, which had a canard-elevon separation of 3 chord lengths; the slipstream impacted the elevon around $90 \%$ of the way down the chord. However, the Mach contour plot (Figure 17) revealed that, at that location, the elevon was impacted by the shock/expansion fan system from the canard. When moved back to a 5-chord length separation, with the slipstream hitting the same location, Side B provided the closer prediction. In Figure 17, notice that the slipstream and shock/expansion system from the canard are relatively close to each other. The slipstream has its greatest effect on the elevon in conditions such as this, which have a relatively small canard-elevon separation. Therefore, in these conditions, when the slipstream impinges on the trailing edge of the elevon, the front of the elevon will either be in or very near to the shock/expansion fan system from the canard. Because of this, the analytical formulation prediction is not valid, as it does not take these shock/expansion fan system effects into consideration. As a result, for cases in which the slipstream strikes the elevon, Side B should be used in the analytical formulation. 


\section{Future Work}

For inviscid calculations, the analytical shock/expansion fan formulation could be made more accurate by allowing for the slipstream and other elevon effects to diminish with distance both away from the canard and perpendicularly away from the slipstream itself. Also, the location of the shock/expansion fan system from the canard could be calculated. Then, if this system is calculated to impact the elevon, flow properties from within the system could be used instead of the downstream flow properties as currently used.

The next phases of this research will be to add real gas and viscous effects to the simulations in order to investigate the amount by which those effects will impact the flow seen by the elevon compared to the effects described in this paper. Among other effects, at some point the expansion fan turning angles will be large enough such that the flow will separate from the airfoils. Also, at high Mach numbers, the gas will begin to dissociate. Modelling these effects may be vital to fully assess the impact the canard will have on the elevon.

\section{Acknowledgements}

The authors acknowledge the help provided by Nathan Scholten (University of Michigan) with the CFD study. This work was supported in part by a grant of computer time from the DoD High Performance Computing Modernization Program at AFRL MSRC. Funds for the Michigan-AFRL Collaborative Center in Control Science (MACCCS) were made available from the Air Force Research Laboratory/Air Vehicles Directorate grant number FA 8650-07-2-3744.

\section{References}

\footnotetext{
${ }^{1}$ Oppenheimer, M. W., Skujins, T., Doman, D. B., and Cesnik, C. E. S., "Canard-Elevator Interactions on a Hypersonic Vehicle," 2008 AIAA Atmospheric Flight Mechanics Conference and Exhibit, AIAA, August 2008.

${ }^{2}$ Lighthill, M. J., "The Conditions Behind the Trailing Edge of the Supersonic Airfoil," Reports and Memoranda No. 1930, 1944, pp. 249-256.

${ }^{3}$ Oppenheimer, M. W., Skujins, T., Bolender, M. A., and Doman, D. B., "A Flexible Hypersonic Vehicle Model Developed with Pistion Theory," 2007 AIAA Atmospheric Flight Mechanics Conference and Exhibit, AIAA Paper No. 2007-6396, August 2007

4 "Equations, Tables, and Charts for Compressible Flow," Tech. Rep. Tech. Rep. NACA-1135, National Advisory Committee for Aeronautics, Ames Aeronautical Laboratory, Moffett Field, CA, 1953.

${ }^{5}$ Anderson, J. D., Fundamentals of Aerodynamics, McGraw-Hill, Inc., 1984.

${ }^{6}$ Bolender, M. A. and Doman, D. B., "Nonlinear Longitudinal Dynamical Model of an Air-Breathing Hypersonic Vehicle," Journal of Spacecraft and Rockets, Vol. 44, No. 2, 2007, pp. 374-387.

7 "CFD++ User Manual," Tech. rep., Metacomp Technologies, Agoura Hills, California, 2008.

8 "Gridgen User Manual," Tech. Rep. Version 15, Pointwise, Fort Worth, Texas, 2007.

${ }^{9}$ Tang, B., "Orthogonal Array-Based Latin Hypercubes," Journal of the American Statistical Association, Vol. 88, No. 424, 1993, pp. 1392-1397.

${ }^{10}$ Cioppa, T. M. and Lucas, T. W., "Efficient Nearly Orthogonal and Space-Filling Latin Hypercubes," Technometrics, Vol. 49, No. 1, 2007, pp. 45-55.

${ }^{11}$ Sanchez, S. M., "NOLHdesigns spreadsheet," 2005. Available online via http://diana.cs.nps.mil/SeedLab, Last accessed 06/27/2008.
} 